\title{
The Difference in Comorbidities and Behavioral Aspects between Internet Abuse and Internet Dependence in Korean Male Adolescents
}

\author{
June-Young Lee', E-Jin Park², Min Kwon ${ }^{3}$, Ji-Hye Choi ${ }^{3}$, Jo-Eun Jeong ${ }^{3}$, Jung-Seok Choi ${ }^{4}$, \\ Sam Wook Choi ${ }^{5}$, Chang-Uk Lee ${ }^{3}$, and Dai-Jin Kim ${ }^{3 凶}$ \\ ${ }^{1}$ Sungil Mental Hospital, Namwon, Republic of Korea \\ ${ }^{2}$ Department of Psychiatry, Incheon St. Mary's Hospital, College of Medicine, The Catholic University of Korea, Incheon, Republic of Korea \\ ${ }^{3}$ Addiction Research Institute, Department of Psychiatry, Seoul St. Mary's Hospital, College of Medicine, \\ The Catholic University of Korea, Seoul, Republic of Korea \\ ${ }^{4}$ Department of Psychiatry, Seoul National University College of Medicine, Boramae Medical Center, Seoul, Republic of Korea \\ ${ }^{5}$ Department of Psychiatry, Gangnam Eulji Hospital, Eulji University, Seoul, Republic of Korea
}

\begin{abstract}
Objective This study examined the differences in psychiatric comorbidities and behavioral aspects in accordance with the severity of Internet addiction in male adolescents.

Methods One hundred and twenty-five adolescents from four middle and high schools in Seoul were enrolled in this study. The subjects were divided into non-addict, abuse, and dependence groups according to a diagnostic interview by psychiatrists. The psychiatric comorbidities and behavioral aspects of subjects were evaluated through psychiatric clinical interviews based on the Diagnostic and Statistical Manual of Mental Disorders (4th edition), the Children's Depression Inventory, the State-Trait Anxiety Inventory, the Internet Addiction Test, and a self-reported questionnaire about behavioral aspects.

Results The psychiatric comorbidity distributions were significantly different in the abuse and dependence groups, particularly in terms of attention-deficit hyperactivity disorder and mood disorder items. The Children's Depression Inventory, the State-Trait Anxiety Inventory, and the Internet Addiction Test scores were also significantly different among the three groups. There were significant differences in 10 of the 20 items of the Internet Addiction Test between the non-addict, abuse, and dependence groups. There were significant differences in seven items between the non-addict and abuse groups, but no differences between subjects in the abuse and dependence groups. Significant differences were observed in three items between the abuse and dependence groups, but there were no significant differences between the non-addict and abuse groups. In terms of behavioral aspects, scores for abusive, sexual, and decreased social interest behaviors were highest in the dependence group, and lowest in the non-addict group. However, the behavioral aspects of decreased interpersonal relationships did not show this difference between groups.
\end{abstract}

Conclusion This study suggests that there are differences in psychiatric comorbidities and behavioral aspects between adolescent males with characteristics of Internet abuse and Internet dependence.

Psychiatry Investig 2014;11(4):387-393

Key Words Internet abuse, Dependence, Comorbidity, Behavioral aspects.

\section{INTRODUCTION}

To date, there are no clear definitions of Internet addiction, and Internet addiction as a distinct entity within the topic of addictive disorders continues to be a subject of debate. Although there are several criteria and tests for Internet addiction, the
Internet Addiction Test (IAT) developed by Young ${ }^{1}$ is the most widely-used assessment tool. The IAT is based on the criteria for pathological gambling described in the Diagnostic and Statistical Manual of Mental Disorders, 4th edition (DSM-IV), ${ }^{2}$ suggesting that Internet addiction is a form of behavioral addiction.

Received: July 15, 2013 Revised: October 14, 2013 Accepted: December 2, 2013 Available online: October 20, 2014

$\triangle$ Correspondence: Dai-Jin Kim, MD

Department of Psychiatry, Seoul St. Mary’s Hospital, College of Medicine, The Catholic University of Korea, 222 Banpo-daero, Seocho-gu, Seoul 137-701, Republic of Korea Tel: +82-2-2258-6086, Fax: +82-2-594-3870, E-mail: kdj922@chol.com

(c) This is an Open Access article distributed under the terms of the Creative Commons Attribution Non-Commercial License (http://creativecommons.org/licenses/by-nc/3.0) which permits unrestricted non-commercial use, distribution, and reproduction in any medium, provided the original work is properly cited. 
Several studies have shown that behavioral and substance addictions have many similarities in diverse aspects. ${ }^{3}$ To evaluate Internet addiction, Anderson and Fortson used modified criteria in a study modeled after the substance-related disorders from the DSM-IV, to evaluate Internet addiction. ${ }^{4,5}$ Using these criteria, Internet addiction is defined as an addictive disorder similar to substance use disorders. Their research implied that, as in cases of substance abuse, Internet addiction may be differentially diagnosed as either abuse or dependence, with distinctive clinical characteristics. However, because that study did not conduct patient interviews, but rather made a diagnosis based on paper surveys, the authors were not able to determine exact psychiatric comorbidities for each patient.

A wealth of research regarding Internet addiction has focused on the psychiatric symptoms and psychiatric comorbidities of the condition. ${ }^{6-8}$ There have been consistent findings regarding the relationship between depressive symptoms and Internet addiction, ${ }^{8-11}$ and many researchers have reported that a range of psychiatric diseases coexist with Internet addiction. ${ }^{12,13}$ An accurate assessment of comorbidity is an essential part of understanding the etiology of Internet addiction, because it is obvious that Internet addiction and psychiatric comorbidity affect each other even though their causal relationship remains unclear. Clinically, accurate assessment of comorbidity is important for appropriate treatment, as well as to predict the prognosis of addicts. Recent studies have indicated that Internet addiction has heterogeneous features in psychiatric comorbidities and behavioral aspects according to gender, age, and the severity of addiction. ${ }^{9,14}$ However, these have been small-scale studies or studies that used only self-reported questionnaires without diagnostic interviews by psychiatrists. If it is clear that abuse and dependence group is showing the difference in terms of psychiatric comorbidities based upon accurate diagnosis by psychiatrists, we will be able to plan the research and therapeutic approach for internet addiction more precisely.

Based on the criteria provided by Fortson, ${ }^{4}$ the current study aims to distinguish Internet abuse and dependence by conducting diagnostic interviews, and to determine the differences between the two groups in terms of psychiatric comorbidities and behavioral aspects. The authors hypothesized that there are differences in psychiatric comorbidities and behavioral aspects between male adolescents with tendencies of Internet abuse and dependence.

\section{METHODS}

\section{Participants}

Data were obtained from four local middle and high schools. Included in this study were subjects who were identified as In- ternet addicts both by IAT scores over $40^{1,15,16}$ as well as by psychiatric diagnosis. Age- and gender-matched subjects who were identified as non-addicts were included as the control group. For the non-addict group, diagnostic interviews about Internet addiction and questionnaires were conducted, but psychiatric comorbidities of subjects were not evaluated in this group. The subjects and their parents provided written informed consent after receiving a full explanation of the study, in accordance with procedures approved by the Institutional Review Board of Seoul St. Mary's Hospital.

\section{Materials}

\section{Internet use}

The degree of Internet use was assessed by two methods. First, all participants took the IAT. The IAT is a 5-point Likert scale composed of 20 items, with each item rating the degree of preoccupation, compulsive use, behavioral problems, emotional changes, and impact on general functioning related to Internet use. ${ }^{1} \mathrm{~A}$ higher score indicates a more severe Internet addiction. Second (and the more important part in this study), five psychiatrists conducted interviews using a modified version of the substance abuse and dependence criteria in the DSM-IV. Our criteria for Internet abuse and dependence are shown in Table 1.

\section{Psychiatric comorbidities}

Psychiatrists assessed the psychiatric comorbidity of subjects with the Structured Clinical Interview for Diagnostic and Statistical Manual of Mental Health Disorders-IV (SCID). In addition, all subjects performed the Korean version of the Children's Depression Inventory (CDI $)^{17}$ and the State-Trait Anxiety Inventory $(\mathrm{STAI})^{18}$ for objective assessment of the severity of comorbidities.

\section{Self-reported questionnaire}

Internet addiction research typically uses a 40 -item self-reported questionnaire about Internet usage. ${ }^{19}$ In this study, four items related to behavioral aspects were added to the questionnaire for additional analysis: 1) Are you becoming more aggressive in the cyber world? (abusive), 2) Are your conversations in the cyber world more sexual in nature? (sexual), 3) Are you interested in your school life? (decreased social interest), 4) What is your relationship with friends? (decreased interpersonal relationship)

All four items were rated on a 5-point Likert scale.

\section{Analysis of data}

Continuous variables were analyzed using an independent sample analysis of the variance (ANOVA) with post hoc mul- 
Table 1. Criteria for Internet abuse and dependence

Internet Abuse: When responses to any item of A as well as both B and C are "yes," a definite diagnosis of abuse is made

A. Has the client experienced the following?

1. Recurrent failure to meet important responsibilities due to Internet use

2. Recurrent Internet use in situations when it is likely to be physically dangerous

3. Recurrent legal problems arising from Internet use

4. Continued usage despite recurrent problems aggravated by Internet use

B. These symptoms have occurred within a 12-month period

C. Client has never met the criteria for dependence

Internet Dependence: When any three responses to A and B are "yes," a definite diagnosis of dependence is made

A. Has the client experienced the following?

1. Tolerance; Behavior related to Internet dependence. Developed tolerance symptoms, such as increased Internet use to get the same desired feeling, or a decrease in desired feeling with the same amount of use.

2. Withdrawal; Experienced withdrawal symptoms in reaction to decreased Internet use that have either interrupted important areas of life functioning or have led to use of similar objects to relieve symptoms.

3. Using the Internet more or for longer periods than intended

4. Desire to or unsuccessful efforts to cut down on Internet use

5. Considerable time spent in using or recovering from the effects of use

6. Important social, work, or recreational activities given up because of use

7. Continued use despite knowledge of problems caused or aggravated by use

B. Have these symptoms been present during the same 12-month period?

Table 2. Demographic characteristics of subjects

\begin{tabular}{|c|c|c|c|c|c|c|}
\hline & \multicolumn{2}{|c|}{$\begin{array}{c}\text { Non-addict } \\
(\mathrm{N}=63)\end{array}$} & \multicolumn{2}{|c|}{$\begin{array}{l}\text { Abuse } \\
(\mathrm{N}=21)\end{array}$} & \multicolumn{2}{|c|}{$\begin{array}{c}\text { Dependence } \\
\quad(\mathrm{N}=41)\end{array}$} \\
\hline & $\mathrm{N}$ & $\%$ & $\mathrm{~N}$ & $\%$ & $\mathrm{~N}$ & $\%$ \\
\hline \multicolumn{7}{|l|}{ School } \\
\hline Middle school & 39 & 61.9 & 16 & 76.2 & 32 & 78.0 \\
\hline High school & 24 & 38.1 & 5 & 23.8 & 9 & 22.0 \\
\hline Age $($ mean \pm SD) & \multicolumn{2}{|c|}{$15.95 \pm 1.29$} & \multicolumn{2}{|c|}{$14.76 \pm 0.83$} & \multicolumn{2}{|c|}{$15.02 \pm 0.82$} \\
\hline
\end{tabular}

tiple comparisons and Bonferroni adjustments. The categorical data was analyzed using Fisher's exact tests.

\section{RESULTS}

\section{Internet abuse and dependence}

Table 2 lists demographic data about the subjects. In the addict group, 21 and 41 subjects were classified as belonging to the Internet abuse group and Internet dependence group, respectively.

\section{Psychiatric comorbidities}

Several psychiatric comorbidities were identified among the Internet addicts. In the total addict group, the most common comorbidity was depressive disorder (38.7\%), followed by attention-deficit hyperactivity disorder (35.5\%), mood disorders other than depressive disorder (12.9\%), anxiety disorder (8.1\%), substance use disorder (4.8\%), impulse control disor- der $(4.8 \%)$, and other (14.5\%). When the addict group was subdivided into abuse and dependence groups, there were further differences in the frequency of comorbidities between the two groups (Table 3 ). The total comorbidity rate was higher in the dependence group (82.9\%) than in the abuse group (81.0\%), but the difference was not statistically significant. The only significant difference between the two groups was in the frequency of attention-deficit hyperactivity disorder. The combination of depressive disorder and other mood disorders into a single category of "mood disorders", revealed a significant difference between the two groups as attention-deficit hyperactivity disorder (Figure 1).

\section{Differences in IAT, CDI, and STAI scores between each group}

Figure 2 shows the differences in CDI, trait anxiety, state anxiety, and IAT scores between the groups. The CDI, trait anxiety, and IAT scores increased in the order of non-addict, abuse, and dependence groups, but the state anxiety scores did not. There were significant differences between each group in the CDI items regarding negative thoughts of self and the future, low self-esteem, suicidal ideation, insomnia, loss of appetite, loss of interest in activities, and difficulty with peer relationships. In particular, there were significant differences in low self-esteem, negative thoughts of the future, and suicidal ideation between the abuse and dependence groups. 
Table 3. Comorbidities of subjects in the Internet abuse and dependence groups

\begin{tabular}{|c|c|c|c|c|c|c|}
\hline & \multicolumn{2}{|c|}{ Abuse } & \multicolumn{2}{|c|}{ Dependence } & \multirow{2}{*}{$\chi^{2}$} & \multirow{2}{*}{$\mathrm{p}$} \\
\hline & $\mathrm{N}$ & $\%$ & $\mathrm{~N}$ & $\%$ & & \\
\hline Attention-deficit hyperactivity disorder & 11 & 52.4 & 11 & 26.8 & 3.96 & $<0.05$ \\
\hline Depressive disorder & 5 & 23.8 & 19 & 46.3 & 2.97 & 0.07 \\
\hline Other mood disorders & 1 & 4.8 & 7 & 17.1 & 1.87 & 0.17 \\
\hline Anxiety disorder & 2 & 9.5 & 3 & 7.3 & 0.09 & 0.56 \\
\hline Other comorbidities & 3 & 14.4 & 12 & 29.3 & 1.83 & 0.15 \\
\hline No comorbidity & 4 & 19.0 & 7 & 17.1 & 0.04 & 0.55 \\
\hline
\end{tabular}

Fisher's exact test was used for statistical comparisons

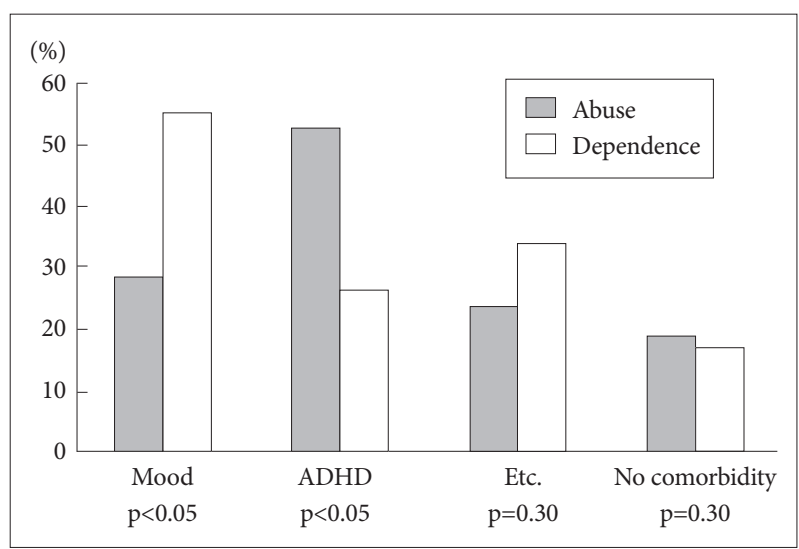

Figure 1. Comorbidities of Internet abuse and dependence groups. Fisher's exact test was used for statistical comparisons. ADHD: attention-deficit hyperactivity disorder.

\section{Differences in IAT items}

Responses to 10 of the 20 IAT items showed significant differences among the non-addict, abuse, and dependence groups. Seven items were significantly different between the non-addict and abuse groups, but not between the abuse and dependence groups. On the other hand, for three items, there were significant differences in the responses of the abuse and dependence groups, but not between the non-addict and abuse groups (Table 4).

\section{Differences in behavioral aspects}

Three items regarding abusive, sexual, and decreased social interest were significantly different between the three groups. However, responses regarding decreased interpersonal relationships were not significantly different (Table 5).

\section{DISCUSSION}

The results of the present study suggest that there are differences in psychiatric comorbidities between subjects in the Internet abuse and dependence groups. In the dependence group, mood disorders, particularly depressive disorder, were a more common comorbidity than attention-deficit hyperactivity dis-

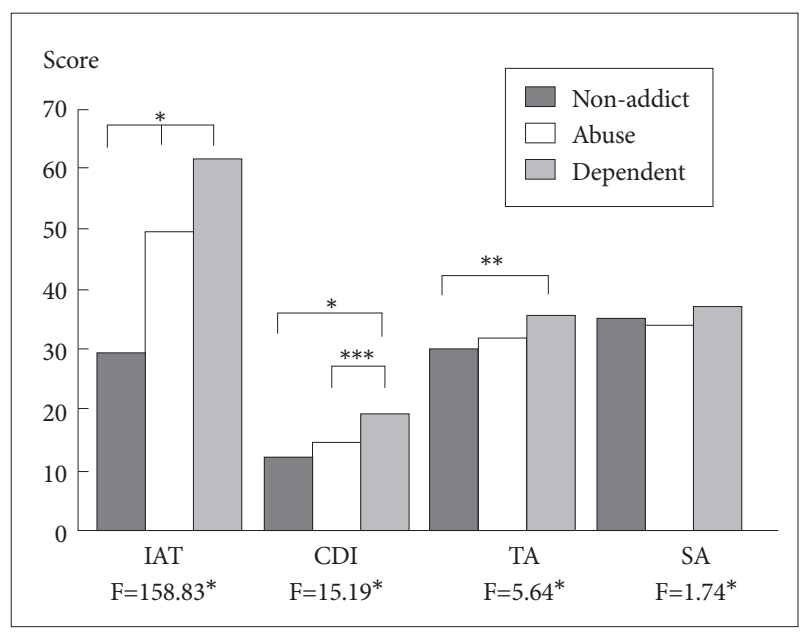

Figure 2. Differences in the CDI, TA, SA and IAT scores between the non-addict, abuse, and dependence groups. ANOVA with post hoc multiple comparisons and Bonferroni adjustments was used for analysis. ${ }^{*} p<0.001,{ }^{* *} p<0.01,{ }^{* * *} p<0.05$. IAT: internet addiction test, CDI: the Children's Depression Inventory, TA: trait anxiety, SA: state anxiety, ANOVA: analysis of variance.

order. On the other hand, in the abuse group, attention-deficit hyperactivity disorder was the most common comorbid disorder. Core symptoms of attention-deficit hyperactivity disorder are "being easily bored" and "having an aversion to delayed rewards."20,21 Internet behavior is characterized by rapid response and immediate rewards, possibly reducing feelings of boredom or providing immediate stimulation and rewards for subjects with attention-deficit hyperactivity disorder. The Internet also offers social support, potential achievement, the pleasure of control, and a virtual world in which adolescents can escape from emotional difficulty in the real world. ${ }^{22-24}$ Accordingly, it appears reasonable that depressive adolescents are more likely to use the Internet to alleviate depression, and that they may suffer more deleterious effects from heavy Internet use. This creates a vicious cycle that may lead to a state of dependence on the Internet falling within the spectrum of Internet addiction. $^{25}$

The significant differences in the CDI and STAI scores among the non-addict, abuse, and dependence groups suggest 
that subjects in the three groups have different levels of depression and anxiety. However, the causality between depression, anxiety, and Internet addiction has not been identified in this study.
20 items of the IAT could subdivided into three groups, according to differences in scores of non-addict, abuse, and dependence. The three subgroups of the IAT indicate that some items are able to identify each stage of addiction (although

Table 4. Differences in Internet Addiction Test items between non-addict, abuse, and dependence groups

\begin{tabular}{|c|c|c|c|c|c|c|}
\hline \multirow{2}{*}{ Items } & \multicolumn{3}{|c|}{ Mean (SD) } & \multicolumn{3}{|c|}{ Multiple comparison } \\
\hline & Non-addict & Abuse & Dependence & $\mathrm{F}$ & $\mathrm{p}$ & \\
\hline 1) Staying online longer than intended & $2.15(0.85)$ & $3.24(0.89)$ & $3.93(1.02)$ & 49.04 & $<0.001$ & Non-addict \\
\hline 2) Neglecting household chores & $1.34(0.60)$ & $2.81(0.68)$ & $3.37(0.97)$ & 98.10 & $<0.001$ & $<$ \\
\hline 3) Preferring the excitement of the Internet & $1.58(0.90)$ & $2.76(0.77)$ & $3.50(0.98)$ & 55.41 & $<0.001$ & $\begin{array}{c}\text { Abuse } \\
<\end{array}$ \\
\hline 4) Forming new relationships with online users & $2.00(1.11)$ & $3.33(1.06)$ & $4.02(0.91)$ & 49.93 & $<0.001$ & Dependence \\
\hline 6) Grades or school work suffer & $1.45(0.76)$ & $2.52(1.25)$ & $3.29(1,42)$ & 36.03 & $<0.001$ & \\
\hline 11) Anticipating going online again & $1.42(0.82)$ & $2.29(1.01)$ & $2.95(1.26)$ & 29.19 & $<0.001$ & \\
\hline 12) Fear of life without the Internet & $1.44(0.64)$ & $2.00(0.77)$ & $2.98(1.21)$ & 37.63 & $<0.001$ & \\
\hline 16) Saying to yourself "just a few more minutes" & $1.71(0.80)$ & $2.52(1.03)$ & $3.50(1.27)$ & 27.64 & $<0.001$ & \\
\hline 18) Trying to hide how long you've been online & $1.27(0.55)$ & $2.33(0.97)$ & $3.21(1.35)$ & 43.72 & $<0.001$ & \\
\hline 19) Spending more time online than going out with others & $1.31(0.50)$ & $2.38(0.92)$ & $3.44(1.16)$ & 75.27 & $<0.001$ & \\
\hline $\begin{array}{l}\text { 5) Others complain to you about the amount of time you } \\
\text { spend online }\end{array}$ & $2.16(0.99)$ & $3.62(0.97)$ & $4.10(0.94)$ & 54.30 & $<0.001$ & $\begin{array}{l}\text { Non-addict } \\
<\end{array}$ \\
\hline 7) Checking email before doing something else & $1.39(0.89)$ & $2.19(1.40)$ & $1.88(1.19)$ & 5.37 & 0.006 & Abuse \\
\hline 8) Reduced job performance or productivity & $1.31(0.62)$ & $2.57(1.12)$ & $2.76(1.37)$ & 30.02 & $<0.001$ & $=$ \\
\hline $\begin{array}{l}\text { 9) Being defensive or secretive when anyone asks you what } \\
\text { you do online }\end{array}$ & $1.32(0.70)$ & $2.05(0.86)$ & $2.37(1.28)$ & 16.09 & $<0.001$ & dienc \\
\hline $\begin{array}{l}\text { 10) Using soothing thoughts of the Internet to block out } \\
\text { disturbing thoughts about life }\end{array}$ & $1.40(0.64)$ & $2.52(1.03)$ & $2.83(1.20)$ & 33.09 & $<0.001$ & \\
\hline $\begin{array}{l}\text { 13) Snapping, yelling, acting annoyed if someone bothers } \\
\text { you while you are online }\end{array}$ & $1.63(0.94)$ & $2.57(1.16)$ & $3.20(1.27)$ & 26.50 & $<0.001$ & \\
\hline 17) Failing attempts to cut down on use & $1.37(0.63)$ & $2.38(1.07)$ & $2.86(1.62)$ & 29.19 & $<0.001$ & \\
\hline 14) Losing sleep due to late-night log-ins & $1.37(0.63)$ & $1.95(1.16)$ & $2.71(1.31)$ & 22.77 & $<0.001$ & Non-addict \\
\hline 15) Feeling preoccupied with the Internet when offline & $1.06(0.25)$ & $1.33(0.80)$ & $2.17(1.34)$ & 21.39 & $<0.001$ & $\begin{array}{c}= \\
\text { Abuse }\end{array}$ \\
\hline 20) Feeling depressed, moody, nervous when you are offline & $1.15(0.42)$ & $1.57(0.75)$ & $2.64(1.29)$ & 32.21 & $<0.001$ & $\begin{array}{c}< \\
\text { Dependence }\end{array}$ \\
\hline
\end{tabular}

ANOVA with post hoc multiple comparisons and Bonferroni adjustments was used for analysis. ANOVA: analysis of variance

Table 5. Distribution of behavioral aspects questionnaire responses from non-addict, abuse, and dependence groups

\begin{tabular}{|c|c|c|c|c|c|c|c|}
\hline \multirow{2}{*}{ Questionnaire } & \multirow{2}{*}{ Group } & \multicolumn{5}{|c|}{ Answer (\%) } & \multirow{2}{*}{$\mathrm{p}$} \\
\hline & & Never & Infrequently & Sometimes & Frequently & Always & \\
\hline \multirow[t]{3}{*}{ Abusive } & Non-addict & 50.8 & 38.1 & 11.1 & 0.0 & 0.0 & \multirow{3}{*}{$<0.001$} \\
\hline & Abuse & 38.9 & 22.2 & 38.9 & 0.0 & 0.0 & \\
\hline & Dependence & 17.9 & 14.3 & 39.3 & 21.4 & 7.1 & \\
\hline \multirow[t]{3}{*}{ Sexual } & Non-addict & 69.8 & 25.4 & 4.8 & 0.0 & 0.0 & \multirow{3}{*}{0.01} \\
\hline & Abuse & 55.6 & 33.3 & 11.1 & 0.0 & 0.0 & \\
\hline & Dependence & 32.1 & 39.3 & 21.4 & 3.6 & 3.6 & \\
\hline \multirow[t]{3}{*}{ Decreased social interest } & Non-addict & 11.1 & 30.2 & 47.6 & 9.5 & 1.6 & \multirow{3}{*}{0.02} \\
\hline & Abuse & 11.1 & 16.7 & 44.4 & 5.6 & 22.2 & \\
\hline & Dependence & 3.6 & 14.3 & 42.9 & 21.4 & 17.9 & \\
\hline \multirow[t]{3}{*}{ Decreased interpersonal relationships } & Non-addict & 22.2 & 60.3 & 17.5 & 0.0 & 0.0 & \multirow{3}{*}{0.15} \\
\hline & Abuse & 33.3 & 55.6 & 11.1 & 0.0 & 0.0 & \\
\hline & Dependence & 21.4 & 39.3 & 35.7 & 3.6 & 0.0 & \\
\hline
\end{tabular}

Fisher's exact test was used for statistical comparisons 
some items may be useful only for identifying normal or addict subjects), whereas some items are able to identify the level of dependence in subjects. In this study, sleep disorders, mood changes, and preoccupation were prominent in the dependence group, but there were no significant differences in these items between the non-addict and abuse groups.

Abusive behavior, sexual behavior, and decreased social interest were more severe in the abuse group than in the nonaddict group, and were most severe in the dependence group. These results are consistent with the results of previous studies. $^{26-28}$ Decreased interpersonal relationships, however, did not show the same pattern as the other behavioral aspects. It appears that subjects in the abuse group have better relationships with others than subjects in the non-addict group. This could be explained in two ways. First of which, the survey did not differentiate the terms 'on-line' friends and' off-line' friends and this resulted in the expansion of the term. In order to clarify this, we will have to clearly distinguish the term, 'off-line' friends from 'on-line' friends before the evaluation. Secondly, this also may be explained by previous reports suggesting that the Internet tends to compensate for the communication difficulties of introverted and withdrawn people. ${ }^{29}$ Information regarding an individual's level of interpersonal relationships before the individual demonstrates characteristics of Internet abuse or dependence should be acquired to accurately assess the effect of the Internet on interpersonal relationships.

This study has some limitations. The first limitation is that the psychiatric comorbidities of subjects in the non-addict group were not evaluated. Due to this limitation, our results do not show the differences in psychiatric comorbidities between the non-addict and addict groups. This point, however, does not detract from the primary purpose of comparing psychiatric comorbidities between Internet abuse and dependence groups. The second limitation is that this study was conducted as a cross-sectional study. A longitudinal prospective study is needed to identify the causality of Internet addiction and psychiatric comorbidities.

In conclusion, there are differences in psychiatric comorbidities and behavioral aspects between male adolescents with tendencies of Internet abuse and dependence. These findings suggest that Internet abuse and dependence have a different core psychopathology. Based on these results, in the future research, we will be able to conduct a large-scale study about the biological and psychological mechanism of internet abuse and dependence. And, in terms of the treatment point of view, if the causality of psychiatric comorbidity is found in internet abuse and dependence group, it will be able to help to prevent the recurrence or worsening of it.

\section{Acknowledgments}

The study was supported by a grant from the Korean Health Technology R\&D Project, Ministry of Health and Welfare, Republic of Korea (HI12 C0113(A120157)).

\section{REFERENCES}

1. Young KS. Caught in the Net: How to Recognize the Signs of Internet Addiction and a Winning Strategy for Recovery. New York: John Wiley \& Sons, Inc.; 1998.

2. American Psychiatric Association. Diagnostic and statistical manual of mental disorders, Fourth Edition. Washington, DC: American Psychiatric Press; 1994.

3. Jon EG, Marc NP, Aviv W, David AG. Introduction to behavioral addiction. Am J Drug Alcohol Abuse 2010;36:233-241.

4. Fortson BL, Scotti JR, Chen YC, Malone J, Del Ben KS. Internet use, abuse, and dependence among students at a southeastern regional university. J Am Coll Health 2007;56:137-144.

5. Anderson KJ. Internet use among college students: an exploratory study. J Am Coll Health 2001;50:21-26.

6. Black DW, Belsare G, Schlosser S. Clinical features, psychiatric comorbidity, and health-related quality of life in persons reporting compulsive computer use behavior. J Clin Psychiatry 1999;60:839-844.

7. Shapira NA, Goldsmith TD, Keck PE Jr, Khosla UM, McElroy SL. Psychiatric features of individuals with problematic internet use. J Affect Disord 2000;57:267-272.

8. Young KS, Rogers RC. The relationship between depression and Internet addiction. Cyberpsychol Behav 1998;1:25-28.

9. Petrie H, Gunn D. Internet "Addiction": the Effects of Sex, Age, Depression and Introversion. London, England: British Psychological Society London Conference Dec 15-16, 1998.

10. Ha JH, Kim SY, Bae SC, Bae S, Kim H, Sim M, et al. Depression and internet addiction in adolescents. Psychopathology 2007;40:424-430.

11. Kim K, Ryu E, Chon MY, Yeun EJ, Choi SY, Seo JS, et al. Internet addiction in Korean adolescents and its relation to depression and suicidal ideation: a questionnaire survey. Int J Nurs Stud 2006;43:185-192.

12. Ha JH, Yoo HJ, Cho IH, Chin B, Shin D, Kim JH. Psychiatric comorbidity assessed in Korean children and adolescents who screen positive for Internet addiction. J Clin Psychiatry 2006;67:821-826.

13. Yoo HJ, Cho SC, Ha J, Yune SK, Kim SJ, Hwang J, et al. Attention deficit hyperactivity symptoms and Internet addiction. Psychiatry Clin Neurosci 2004;58:487-494.

14. Ko CH, Yen JY, Chen CC, Chen SH, Yen CF. Gender differences and related factors affecting online gaming addiction among Taiwanese adolescents. J Nerv Ment Dis 2005;193:273-277.

15. Laura W, Marry M. The psychometric properties of the internet addiction test. Cyberpsychol Behav 2004;7:443-450.

16. Panayiotis P, Miranda JW. Evaluation of the psychometric properties of the Internet Addiction Test in a sample of Cypriot high school students. Eur J Psychol 2012;8:327-351.

17. Cho SC. Development of the Korean form of the Kovacs' Children's Depression Inventory. J Korean Neuropsychiatr Assoc 1990;29:943-956.

18. Spielberger CD, Gorsuch RL, Lushene RE. Manual for the State-Trait Anxiety Inventory. Palo Alto: Consulting Psychologist Press; 1970.

19. Kim CT, Kim DI, Park JK. A Study on Internet Addiction Counseling and the Development of Prevention Program. Seoul: National IT Industrial Promotion Agency; 2002.

20. Castellanos FX, Tannock R. Neuroscience of attention-deficit/hyperactivity disorder: the search for endophenotypes. Nat Rev Neurosci 2002;3:617-628.

21. Diamond A. Attention-deficit disorder (attention-deficit/ hyperactivity disorder without hyperactivity): a neurobiologically and behaviorally distinct disorder from attention-deficit hyperactivity disorder (with hyperactivity). Dev Psychopathol 2005;17:807-825.

22. Suler JR. To get what you need: healthy and pathological Internet use. 
Cyberpsychol Behav 1999;2:385-393.

23. Tichon JG, Shapiro M. The process of sharing social support in cyberspace. Cyberpsychol Behav 2003;6:161-170.

24. Leung L. Net-generation attributes and seductive properties of the Internet as predictors of online activities and Internet addiction. Cyberpsychol Behav 2004;7:333-348.

25. Kraut R, Kiesler S, Boneva B, Cummings J, Helgeson V, Crawford A. Internet paradox revisited. J Soc Issues 2002;58:49-74.

26. Kim EJ, Namkoong K, Ku T, Kim SJ. The relationship between online game addiction and aggression, self-control and narcissistic personali- ty traits. Eur Psychiatry 2008;23:212-218.

27. Ko CH, Yen JY, Liu SC, Huang CF, Yen CF. The associations between aggressive behaviors and Internet addiction and online activities in adolescents. J Adolesc Health 2009;44:598-605.

28. Cooper A, Scherer CR, Boies SC, Gordon BL. Sexuality on the Internet: from sexual exploration to pathological expression. Prof Psychol Res Pract 1999;30:154-164.

29. Allison SE, von Whalde LV, Shockley T, Gabbard GO. The Development of the Self in the Era of the Internet and Role-Playing Fantasy Games. Am J Psychiatry 2006;163:381-385. 